\title{
Am Vorabend der Situlenkunst - Ein Beitrag zur Bilderzählung in der östlichen Hallstattkultur als Ausdruck religiösen Denkens am Beginn der Eisenzeit
}

\author{
On the eve of Situla Art: Pictorial narratives in the East Hallstatt \\ Culture as an expression of religious thinking at the onset of the Iron Age
}

\author{
Susanne Stegmann-Rajtár
}

\begin{abstract}
Abstrakt
Die Ursprünge der Figuralkunst kann man weit bis in die Urnenfelderzeit hin zurückverfolgen und von subfigürlichen Motiven ableiten. Wesentlich abweichend zu der bis jetzt bekannten figuralverzierten Keramik aus Grabhügeln der östlichen Hallstattkultur ist jedoch eine außergewöhnliche Fundart im Bereich der hallstattzeitlichen Siedlung von Pusté Úl'any (Kr. Galanta), Flur "Hlavná ulica", die sich im Randgebiet der Kalenderberggruppe, genauer im Kontaktgebiet mit der Lausitzer Kultur befindet. Im Mittelpunkt dieses Beitrags steht der Fund eines figürlich verzierten Knochplättchens aus einer Siedlungsgrube. Ein Zusammenhang mit Werken der Situlenkunst ist nicht zu bestreiten. Das Knochenplättchen mit zoomorpher Darstellung von zwei stark stilisierten Hirschkühen ist für pizenische und etruskische Kunst charakteristisch.
\end{abstract}

\section{Schlagwörter}

Ältere Eisenzeit, östliche Hallstattkultur, mittleres Donaugebiet, Situlenkunst, figürliche Darstellung

\begin{abstract}
The origins of figural art can be traced back deep into the Urnfield Period and derived from sub-figural motifs. However, the presently known ceramic vessels with figural decoration from burial mounds of the East Hallstatt Culture differ considerably from the unique find of a bone plate found in the settlement at Pusté Úl'any (Galanta District), "Hlavná ulica" site, which extended in the peripheral zone of the Hallstatt-Period Kalenderberg Group, in the zone of contact with Lusatian Culture. The find with figural decoration was discovered in one of the settlement features and its analysis and evaluation are topic of this paper. The artefact is clearly related to unique pieces of the Situla Art. The bone plate bears a zoomorphic depiction of two stylised hinds, which was characteristic of the Picentinian and Etruscan Art.
\end{abstract}

\section{Keywords}

Early Iron Age, East Hallstatt Culture, Middle Danube Region, Situla Art, figural depictions 


\section{Einleitung}

Bildliche Darstellungen als archäologische Quelle sind ein allgemein wichtiger Beleg für die Kenntnis der Lebensart und Kunstäußerung in vor- und frühgeschichtlicher Zeit. Auch während der älteren Eisenzeit, in einer Zeit der schriftlosen Kultur, waren sie ein weit verbreitetes Phänomen. Im Raum zwischen Oberitalien und Donau waren in der Hallstattzeit ganz besondere, figürlich verzierte Fundarten verbreitet. Es sind Werke die wir zusammenfassend mit der Bezeichnung „Situlenkunst“ benennen, auch wenn sich dabei deutlich verschiedene Kreise abzeichnen. Das Verbreitungsgebiet der Hallstattkultur ist dabei als Randzone zu den mittelmeerischen Hochkulturen aufzufassen (Abb. 1). Häufigste Bildträger sind vor allem bronzene Prestigegüter wie Eimer/Situlen sowie andere Bronzegefäße, ferner Deckel, Gürtelbleche, Dolchscheiden und andere Metallarbeiten, die wir auch als Ausdruck religiösen Denkens interpretieren (Frey 1966; 1969; Huth 2003). Die letzten Ausläufer der Situlenkunst finden sich mehr in den Randzonen des Verbreitungsgebietes. Das beste Zeugnis dafür, dass es in der Endphase der Hallstattzeit noch zu einer reichen kulturellen Entwicklung kam, bietet die jüngere Situlenkunst (5.-4. Jahrhundert vor Chr); die Funde dieser Zeit stammen zum großen Teil von Opferplätzen und sind deshalb meistens nur in Fragmenten erhalten geblieben. Zu einem Ende kommt dieses Kunstschaffen durch die keltische Wanderung und die Überschichtung durch die Latènekultur (Frey 2005; 2007; Huth 2003).

Eine zentrale Stellung der Situlendenkmäler nehmen die toreutischen Arbeiten aus Este ein. Die Entstehung der älteren Situlenkunst fällt in Este in die 2. Hälfte des 7. Jahrhundert vor. Chr. und wirkte sich bis in die Gebiete nordöstlich der Alpen aus. Anregungen zur Entstehung der frühen Bilderzählung aus Este kamen aus dem südlich benachbarten Etrurien. Bei der figürlich verzierten Toreutik von Este ist von besonderem Interesse, dass sie sich über einen ziemlich langen Zeitraum verfolgen läßt. In Werken des estensischen Kunstkreises war hauptsächlich das Tierbild vorherrschend. Neben Situlen (Abb. 6; 7) sind vor allem Dolchscheiden (Abb. 4) und Gürtelbleche (Abb. 5) Bildträger (Huth 2003; Frey 1969; ders. 2005; Parzinger 1991; Starè 1955). Die Verbreitung dieser Werke reicht im 5. und 4. Jahrhundert vor. Chr. ebenfalls von Tirol bis Krain und im Süden bis Bologna. Die überwiegende Zahl stammt aber aus der Nekropole von Este (Frey 1969). Einige Arbeiten sind sicher älter als die etruskische und griechische Kolonisation in der Poebene. Die Tradition dieser Kunst wird auch in späterer Zeit fortgesetzt, da in venetischen Heiligtümern zahlreich Votivbleche angetroffen wurden (Frey 1966, 56). Die letzten Reste von figuralverzierten Situlen dürften dann noch einige Zeit als Amulette oder Zierbleche Verwendung gefunden haben (Kriss 1962). Im Heiligtum von Vicenza wurden etwa 200 verzierte, überwiegend rechteckige Kleinbleche entdeckt. Auf den häufigen Fundstücken fehlen jedoch weitgehend szenische Schilderungen, wie wir sie in der Situlenkunst haben (Roth 1978).

Die Kunst des Este-Kreises wurde dann an ihre nördliche Peripherie weiterverbreitet (Sesto Calende, Kleinklein), wie uns ausführliche Forschungen von O.-H. Frey und in späterer Zeit von H. Parzinger (Parzinger 1991; Parzinger - Nekvasil - Barth 1995, 115-127) darlegen (Abb. 1). Die nördlichste Fundstelle dieser Gruppe stellt die bekannte Býči skála Höhle in Südmähren dar. Das hier gefundene kleine Fragment vom Bronzegefäß mit Darstellung eines Aulosbläsers kennt seine nächste Paralellen im Gräberfeld von Kleinklein (Parzinger - Nekvasil - Barth 1995, 122-127). In den zentralen Fundstellen der südostlichen Hallstattkultur, wie z. B. in Stična, Vače, Magdalenska gora oder Klein- 
klein, wurden in erster Linie die Bronzeblecharbeiten, vor allem Eimer, Gürtelbleche, Helme u.a. mit figuralen Darstellungen verziert (Abb. 1. 4. 5). Eine weitere Gruppe von Denkmälern bilden kleinplastische Darstellungen, wie beispielsweise der Kultwagen von Strettweg, die Bleifigürchen von Frög oder die Tonplastiken von dem Kegelhalsgefäß aus Gemeinlebarn. Sie fehlen auch nicht in Gebieten weiter nördlich im Randgebiet der Hallstattkultur, auch wenn sie dort seltener vorkommen und ohne genaueren Zusammenhang überliefert sind (Studeniková 2004). Kleinplastische Darstellungen aus diesem Gebiet sind vereinzelt und ohne genauere Fundumstände überliefert, gelegentlich sind sie aus Gräbern belegt (Abb. 1. 3).

\section{Zur figuralverzierten Keramik des Nordostalpengebietes}

Figuralverzierte Keramik mit Einzelfiguren war dabei nicht alleine im Ostalpengebiet, sondern auch in Süddeutschland, Böhmen, Nordmähren sowie Mittelschlesien verbreitet (Abb. 1, 1). Dagegen bleiben verzierte Tongefäße mit szenischen Elementen, die aufgemalt oder eingeritzt wurden, lediglich auf den Bereich der ostalpinen Kalenderberggruppe beschränkt und gerade sie stehen auch den Denkmälern der besagten Situlenkunst am nächsten (Parzinger - Nekvasil - Barth 1995). Solche figürlichen Darstellungen auf Keramik der Kalenderberggruppe sind hauptsächlich im Begräbnisritual vornehmer Persönlichkeiten, die in Grabhügeln bestattet wurden, kennzeichnend. Die Ursprünge der Figuralkunst kann man weit bis in die Urnenfelderzeit zurückverfolgen und sind von subfigürlichen Motiven abzuleiten (Nebelsick 1992, 114-125).

Figürlich verzierte Keramik ist vor allem in reichen Frauen- und Männergräbern der Kalenderberggruppe belegt, die sich durch reiche
Geschirrsätze auszeichnen. Wenn man die dargestellten Motive untersucht, dann lässt sich eine Verbindung zur bildlichen Überlieferung auf den figuralverzierten Blecharbeiten der Situlenkunst aus dem 7. und 6. Jahrhundert v. Chr. herstellen. Es liegt nahe, die Darstellungen auf Keramik mit bestimmten Bestattungszeremonien in Zusammenhang zu bringen - das auf figuralverzierten Situlen zum Thema bildlicher Darstellungen wurde. Das belegt der Vergleich des figürlich verziertenTongefäßes von SopronBurgstall Hügel 28 (Eibner-Persy 1980, Taf. 28) mit den Darstellungen auf Bronzesitulen, beispielsweise von Magdalenska gora (Abb. 6) und Vače (Abb. 7). Vergleichbare Kunstäußerung auf Keramik dieser Art im Verbreitungsgebiet der südostalpinen Hallstattkultur fehlt dagegen interessanterweise bis jetzt vollkommen (Abb. 1, 2). Die Grabausstattung in vergleichbar reichen Hügeln der südostalpinen Hallstattgruppen, in den Gräbern der sog. Oberschicht, waren zu diesem Zeitpunkt andere außergewöhnliche Beigaben vorherrschend (Teržan 1990). Deshalb ist auch die Gefäßform oft mehr an den italischen Raum angelehnt, z. B. das Gefäß auf drei Beinen von Nové Košariská oder die Gefässe mit Tonketten, als an die Keramik der südostalpinen Hallstattkultur. Dazu gehört ferner die Nachahmung eines Bronzegefässes von Biely Kostol ${ }^{1}$. Die Prunkgefässe von Nové Košariská und Biely Kostol waren alles tönerne Nachahmungen von bronzenen Vorbildern aus dem Kulturkreis von Este sowie Etruriens. Dieser Kulturkontakt mit nordost- und Mittelitalien, wie Forschungen zeigen, fällt in einen frühen Abschnitt der älteren Hallstattzeit (Siegfried-Weiß 1979).

In der südostalpinen Hallstattkultur entwikkelten sich seit dem Übergang von der jüngeren Urnenfelder- zur Hallstattzeit bedeutende befestigte Siedlungsplätze mit dazugehörigen reichen Grabhügelnekropolen. Aufgrund kultureller Anregungen aus dem griechischen 


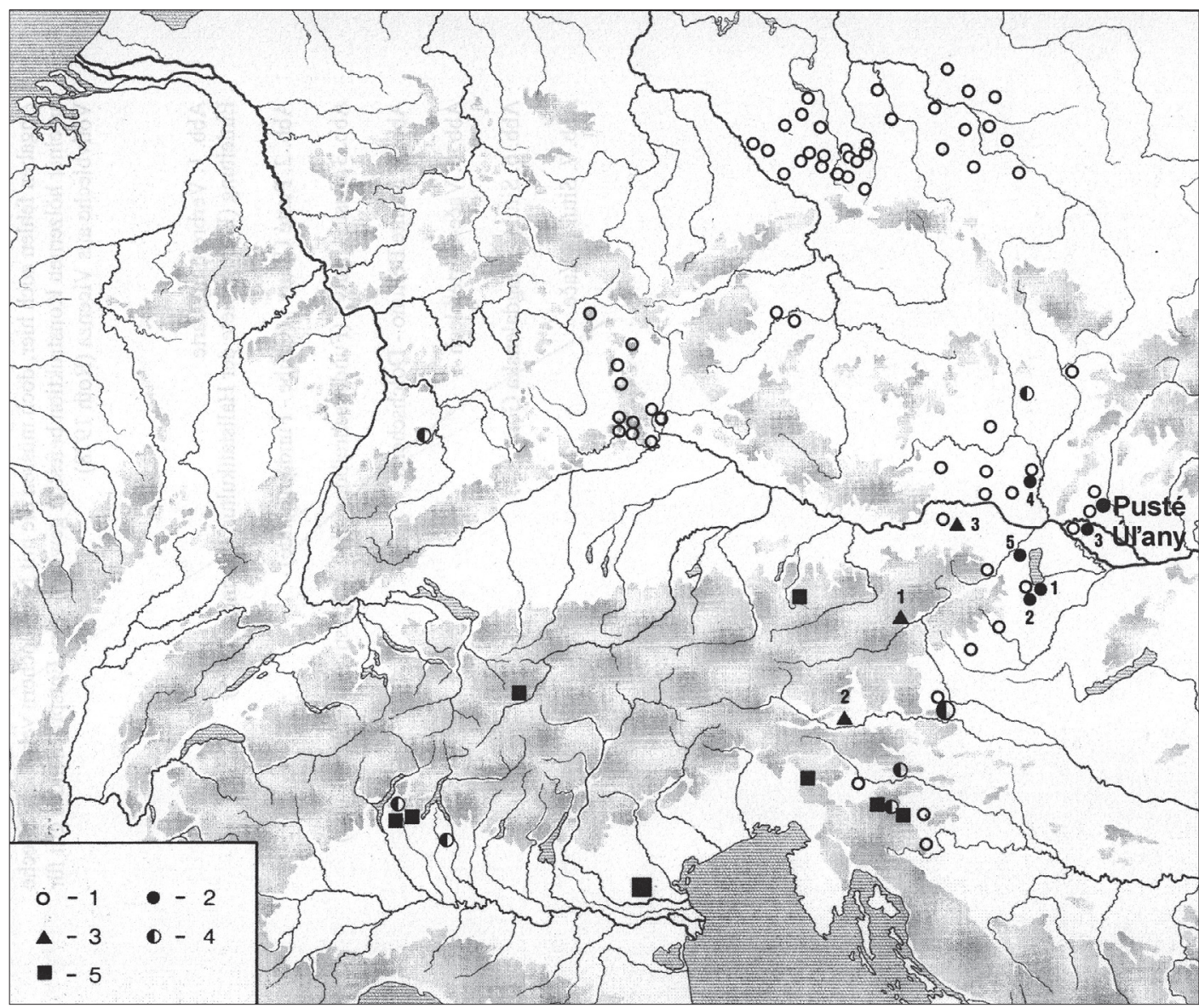

Abb. 1. Verbreitung der Figuralkunst und szenischer Darstellungen. 1 - Figuralverzierte Keramik, nur Einzelfiguren. 2 - Figuralverzierte Keramik mit szenischen Elementen. 3 - Kleinplastische Szenen. 4 - Toreutik im alpinen Punkt-Buckel-Stil. 5 - Toreutik im frühen Este-Stil (nach Parzinger - Nekvasil - Barth 1995, 124, Abb. 2). Ergänzt ist die Fundstelle von Pusté Úlany (Westslowakei) mit dem reliefverzierten Knochenplättchen.

sowie italischen Raum und dem Handel mit Prestigeobjekten wurden einige dieser Siedlungsplätze im Laufe der Zeit zu bedeutenden wirtschaftlichen und politischen Machtzentren. Die außergewöhnlichen bronzenen Fundarten gelangten aus benachbarten Hochkulturen in reich ausgestattete Gräber der südostalpinen Hallstattkultur, wo sie den Status hochrangiger Personen kennzeichneten. Aus den Randgebieten der nordostalpinen Hallstattkultur kennen wir sie dagegen nur ausnahmsweise und wenn, dann nicht aus Gräbern. Mehrmals handelt es sich bei Prestigeobjekten um Einzelfunde (Teržan 1986; Teržan 1990).

Von besonderer Bedeutung für die Beurteilung der Kulturkontakte zwischen der Kalenderberggruppe und den südlich anschließenden Gebieten sind die figuralen Kunstäußerungen auf Keramikgefäßen, überwiegend auf großen Kegelhalsgefässen. Ein Teil der aus Mitteleuropa bekannten Motive und Symbole setzt einheimische Traditionen der Urnenfelderbronzezeit fort, andere entstanden unter dem Einfluss fremder, vor allem südlicher und süd- 


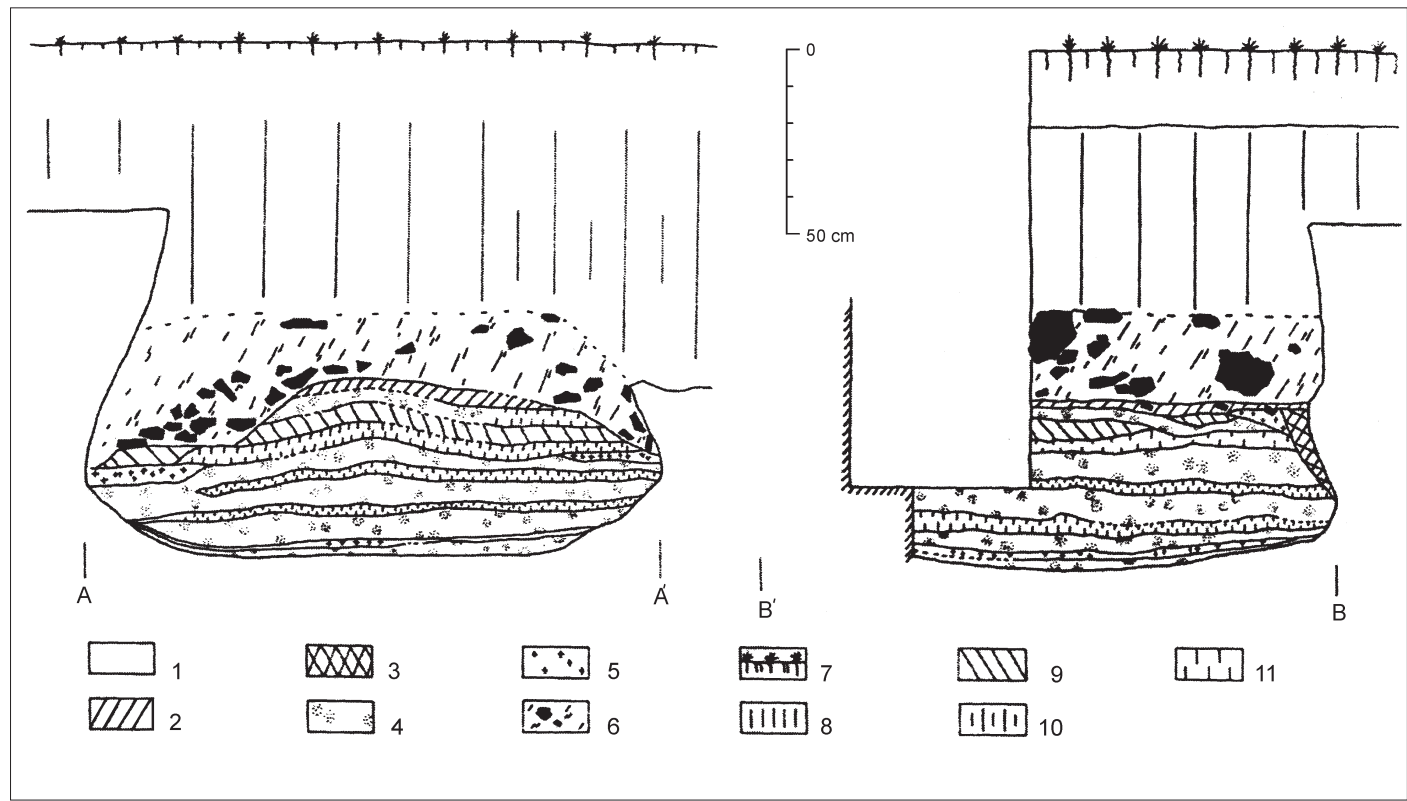

Abb. 2. Profil der Siedlungsgrube von Pusté Úl'any. 1 - gelber Lehmboden, 2 - graue Asche vermischt mit rotbraunem gebrannten Boden, 3 - dunkelbrauner Boden vermischt mit gelbem Lehmboden, 4 - hellgraue Asche, 5 - verkohlte Holzreste, 6 - rotbrauner gebrannter Boden mit Resten von Hüttenlehm, 7 - dunkelbrauner Boden, 8 - graubrauner Boden, 9 - gelber Lehm vermischt mit braunem Lehm und Asche, 10 - dunkler Humusboden, 11 - hellroter gebrannter Lehm (nach König 2003, Abb. 2).

östlicher Anregungen. Einmalig ist die bekannte und in der Literatur oft besprochene figürliche Darstellung einer Webszene auf einem Gefäß aus Hügel 27 von Sopron-Burgstall, die auf die bedeutende Stellung der Frau in der Kalenderberggruppe hinweist. Mehrere Interpretationen belegen die Symbolik dieser Szene: Das Weben des Totengewands und die drei Schicksalsgöttinnen - Moirai, die über das Schicksal entscheiden (Teržan 1986; 1990; Stegmann-Rajtár 2005a). Ähnliche mythologische „Erzählung“ der Kalenderberggruppe kennen wir auch von weiteren wichtigen Fundstellen, beispielsweise von Loretto, Rabensburg und Sopron-Warischberg, sowie auch aus anderen seit langem bekannten Grabhügeln der Kalenderberggruppe nördlich der Donau, im Bereich Ostösterreichs (Nebelsick 2007, 9-128) und der Südwestslowakei, beispielsweise von Nové Košariská, Janíky-
Dolné Janíky (Studeniková 1996), Reca (Abb. 1,2) und in jüngster Zeit aus dem bis jetzt am nördlichsten liegenden Bestattungsplatz von Biely Kostol (Urminský 2001).

Die hallstattzeitlichen Grabhügelgruppen nördlich der Donau, wie es durch neueste Grabungen belegt ist, wurden in unmittelbarer Nachbarschaft zu offenen Siedlungsplätzen angelegt. Einige von diesen Siedlungsplätzen haben sehr reiches Fundmaterial erbracht, und auch im Fall, dass sie nicht immer vollständig freigelegt werden konnten, weisen ganz besondere Fundarten auf den Wohlstand ihrer Bewohner, der sich auch im aufwendigen Grabbau und reicher Beigabenausstattung widerspiegelt. Eine von ihnen ist die vor kurzem zum Teil ausgewertete Siedlung von Nové Košariská ( $B e$ lanová - Čambal - Stegmann-Rajtár 2007). Der fruchtbare Boden der südwestslowakischen 
Tiefebene führte zu einer intensiven Besiedlung in der Hallstattzeit. Zahlreiche neue, bis jetzt nur aus Luftbildern festgestellte Grabhügel sind bekannt, viele wurden bedauerlicherweise schon zerstört (Belanová - Čambal - StegmannRajtár 2007, 423, Anm. 1).

\section{Zu den Funden einer Opfergrube (?) im Bereich der Siedlung von Pusté Úlany (Westslowakei)}

Wesentlich abweichend zu der bis jetzt bekannten figuralverzierten Keramik aus Grabhügeln ist eine außergewöhnliche Fundart im Bereich der hallstattzeitlichen Siedlung von Pusté Úlany (Kr. Galanta), Flur „Hlavná ulica“, die sich im Randgebiet der Kalenderberggruppe (Abb. 1), genauer im Kontaktgebiet mit der Lausitzer Kultur befindet (Stegmann-Rajtár 2002, 254). Jedoch ist die Ausdehnung der Siedlung bedauerlicherweise bis jetzt nur durch einige Oberflächenfunde belegt. Die in unmittelbarer Nachbarschaft liegenden Grabhügel der Kalenderberggruppe sind 1981 durch Forschungen von Etela Studeníková bekannt geworden (Studeniková 1981; Veliačik - Romsauer 1994, 155).). Die Rettungsgrabung in der Siedlung wurde 2002 von Tomáš König geleitet und konzentrierte sich auf die Freilegung einer trapezförmigen Siedlungsgrube (Abb. 2). Nach der Auswertung der Befunde und des Fundmaterials selbst kam der Ausgräber zum Schluß, daß es sich um keine gewöhnliche Siedlungsgrube handeln kann, sondern vielmehr um eine Grube mit Kultcharakter (König 2003; 2005). Eine besondere Stellung nimmt vor allem der außergewöhnliche Fund in dieser Grube ein nämlich das reliefverzierte Knochenplättchen (Abb. 3, 4). Bis jetzt liegen keine Parallelen aus der regionalen hallstattzeitlichen Entwicklung in der Westslowakei vor. Auf dem 4,5 × 3,2 cm großen, rechteckigen Knochenplättchen sind zwei übe- reinander geordnete Hirschkühe dargestellt, beide stark stilisiert. Die runde Durchlochung in einer Ecke belegt, dass es ursprünglich auf einer Unterlage aus organischem Material, vielleicht aus Holz oder Leder, befestigt wurde. Ein Zusammenhang mit Werken der Situlenkunst ist auf jeden Fall nicht zu bestreiten. Es steht fest, dass das Plättchen mit zoomorpher Darstellung von zwei Hirschkühen für pizenische und etruskische Kunst charakteristisch ist (Kriss 1962, 88). Weitere Parallelen liegen auch aus dem westserbischen Bereich vor, wie noch w. u. ausgeführt wird.

Es ist jedoch von Bedeutung, dass in der Siedlungsgrube nicht nur das Knochenplättchen im Situlenstil (Abb. 3, 4) in Begleitung von Keramik der lokalen Kalenderberggruppe gefunden wurde (König 2003; Abb. 3-9), sondern auch weitere bedeutende Funde: Zwei tönerne Tierplastiken (Abb. 3, 1-2) sowie das Fragment einer Spiralplattenfibel (Abb. 3, 3). Die Grube war in den gewachsenen Lößboden eingetieft und es wurden in ihr mehrere, voneinander getrennte Ascheschichten entdeckt. In ihrem oberen Teil wurde eine Brandschicht mit braunroter Erde, ferner Scherben, Tierknochen und Fragmente von Hüttenlehm festgestellt, danach folgten abwechselnd verbrannte Erdschichten mit feinen Körnern hellroter Farbe und graufarbige Ascheschichten mit Funden (Abb. 2). Die Funde lagen in unterschiedlicher Tiefe (Abb. 3: 1-4). Die Tierplastiken in 1,26 m Tiefe, das Knochenplättchen in 1,00 m Tiefe und die Nadel lag 0,95 m tief von der Oberfläche (König 2003). Vom Ausgräber wird die Siedlungsgrube mit den außergewöhnlichen Fundarten als Opferschacht interpretiert, wobei er der Meinung ist, dass sie über einen längeren Zeitraum, also wiederholt benutzt wurde (König 2003). Die durch sterile Schichten getrennten Ascheschichten lassen nach dem Ausgräber den Gedanken zu, dass die Grube sehr wahrscheinlich mit Kulthandlungen im 


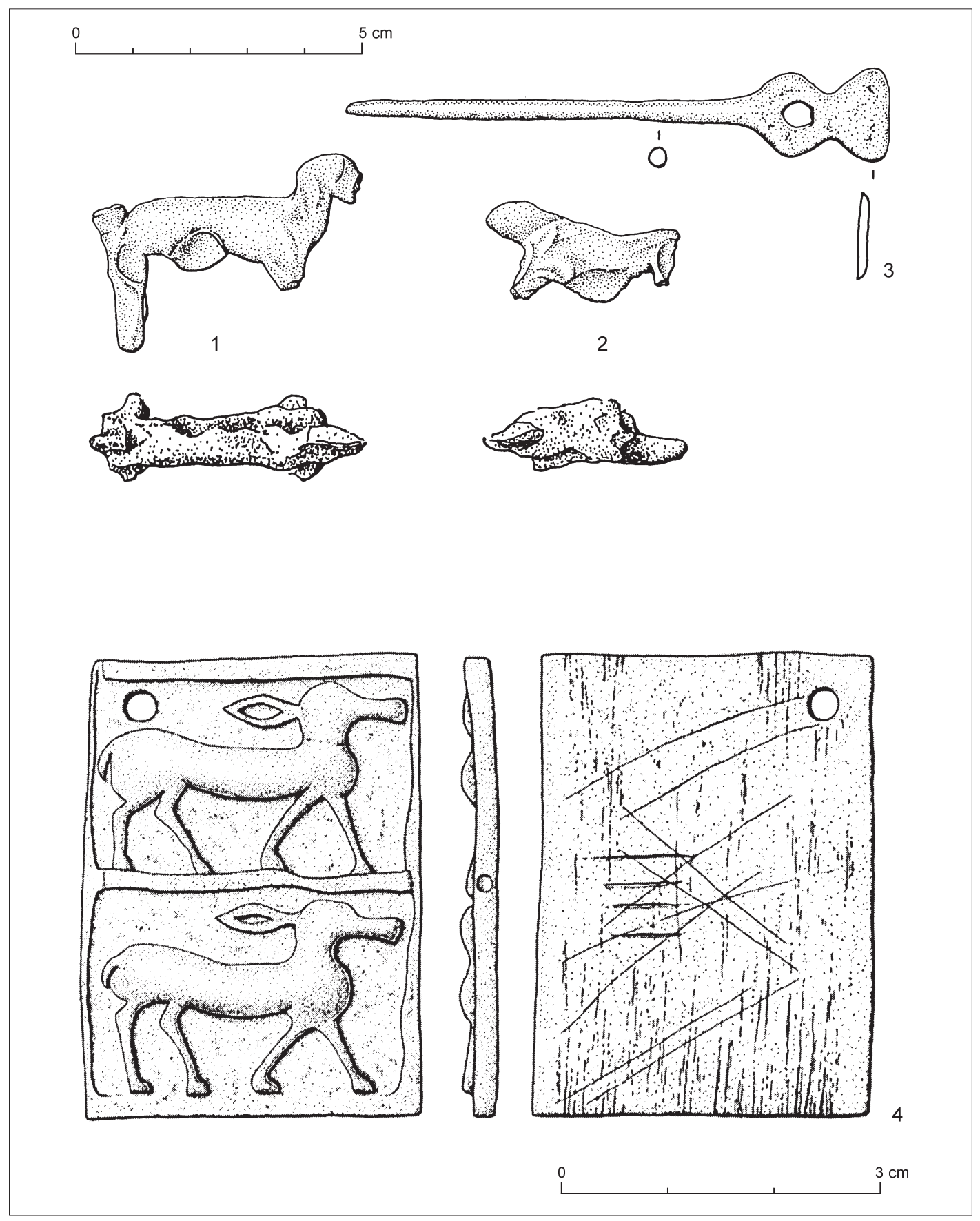

Abb. 3. Auswahl der Funde aus der Siedlungsgrube von Pusté Úl'any. 1-2 Ton, 3 Bronze, 4 Knochen (nach König 2003, Abb. 10; 11). 


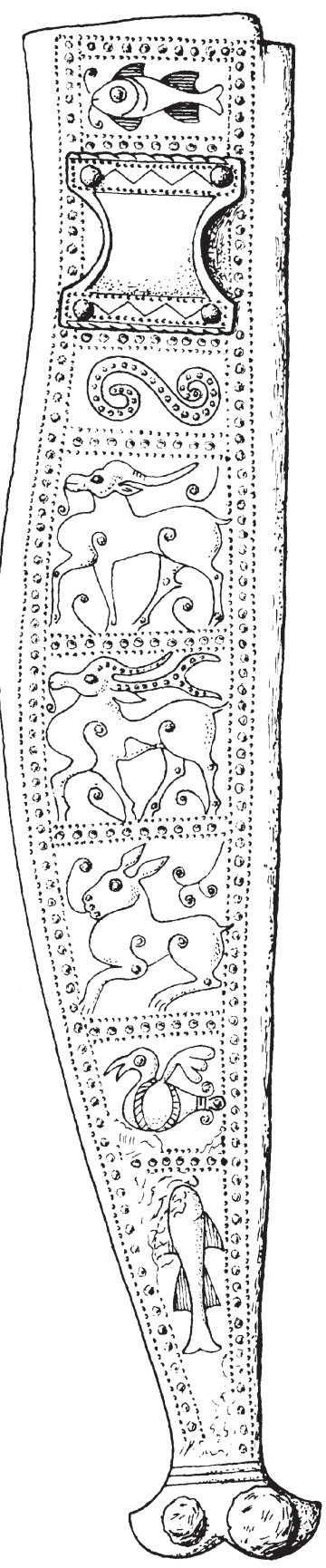

Abb. 4. Dolchscheide von Belluno (nach Frey 1966, Abb. 4). 
Zusammenhang gebracht werden kann. Spuren einer Konstruktion wurden jedoch nicht beobachtet. Das zahlreiche keramische Scherbenmaterial besteht aus einem fragmentierten Kegelhalsgefäß mit geometrischer Graphitbemalung, ferner aus Schalen sowie Töpfen und kann den Stufen HaC bis HaD 1 zugeordnet werden (König 2003, Abb. 3-9). Die Keramik entspricht der lokal geprägten östlichen Hallstattkultur, d.h. der Kalenderberggruppe und der Hallstattgruppe des mittleren und nordöstlichen Transdanubiens (Stegmann-Rajtár 2005a; 2009).

In der Grube von Pusté Úlany befand sich ferner die bereits erwähnte Spiralplattenfibel (Spindlersfelderfibel), von der jedoch nur die ruderförmige Nadel erhalten blieb (Abb. 3, 3). Wegen des Fehlens des Bügels ist eine genauere Typen- und deshalb auch eine zeitliche Einordnung nicht möglich. Diese Fibel kann nur rahmenhaft in die ältere Urnenfelderzeit eingeordnet werden (Paulik - Chropovský 1971; Řihovský 1993; Reich 1997). In der Nähe der Fundstelle befand sich außerdem eine befestigte Siedlung der Čaka-Kultur (König 2003, 117; Veliačik Romsauer 1994, 156) mit der sehr wahrscheinlich auch der Besiedlungshorizont der Fibel in $\mathrm{Zu}-$ sammenhang stehen kann. Spiralplattenfibeln sind auch aus der befestigten Höhensiedlung in Plavecké Podhradie „Pohanská“ westlich des Karpatenbeckens, in Nähe der March bekannt. Zeitlich gehört sie in die Velatice und in die frühe Podoler Kultur und liegt im Überschneidungsgebiet mit der Lausitzer Kultur. Eine Spiralplattenfibel, vergesellschaftet mit einem kimmerischen Dolch vom Gamów-Typ, war auch im gleichnamigen Depotfund in Schlesien vertreten, wo sie in den $\mathrm{HaB} 1$ - zeitlichen Jenišovice-Horizont datiert (Metzner-Nebelsick 2002, 374). Es ist jedoch problematisch, ob die Fibel wirklich als eine „Opfergabe“ bezeichnet werden kann, vielleicht eben nur im Zusammenhang damit, dass auch andere ungewöhnliche Funde in die Grube mit Ascherschichten gelangten. Vermutlich kann man sie nicht als Zufallsfund betrachten. Wenn man bedenkt, daß die Situlen der Spätzeit nicht aus Gräbern, sondern eben viel mehr aus Brandplätzen/Opferplätzen stammen, wie Hermann Parzinger schreibt (Parzinger - Nekvasil - Barth 1995, 204), dann wäre auch dieser einmalige Fundplatz aus der Slowakei in diesem Zusammenhang wohl vorstellbar.

Zwei weitere, nicht weniger bedeutende Funde lagen in der Grube: Fragmente von kleinen zoomorphen Tierfigürchen aus Ton (Abb. 3, 1.2). Vergleichbare Tierplastiken sind auch aus den nahe gelegenen urnenfelderzeitlichen Siedlungen Pobedim (Studeniková - Paulik 1983, Taf. 54:1) sowie aus der befestigten Siedlung Devín (Plachá - Furmánek 1975, Abb. 3; Kmetová - Stegmann-Rajtár 2014, 156) bekannt. Auch diese Funde mögen den Gedanken aufkommen lassen, dass es sich tatsächlich um einen Grube mit Kultcharakter handeln könnte (Studeniková 2004, 366-367). Mit der Frage der tönernen Tierplastik hat sich auch Carola Metzner-Nebelsick ausführlich beschäftigt, vor allem im Zusammenhang mit der Problematik der Verbreitung sog. transkarpatischer Gorodiščen: „Es bleiben kommunikative Strukturen lebendig, durch gemeinsame Aspekte religiöser Praktiken - Deponierung von Tierfigürchen in Siedlungen“ (Metzner-Nebelsick 1998, 396-397, Abb. 27, Anm. 49). Kleine tönerne Tierfigürchen belegen karpatenübergreifende kulturelle Kontakte während der frühen Eisenzeit, wobei ihre religiös-kultische Bedeutung nicht in Frage gestellt wird. Sie waren im ganzen Karpatenbekken bis in das mittlere Dnestr-Gebiet verbreitet. Ihre Niederlegungskontexte, die ihre rituelle Bedeutung unterstreichen, variieren ebenso wie ihre chronologische Stellung. Neben der Deponierung in der Nähe von Herdstellen, kommen sie auch in Gruben (teils in eindeutig rituellem Kontext) und in Hütten vor, und werden häufig zusammen mit einer Aschenkonzentration 
vorgefunden; oder mit Aschenhaufen zusammen mit Spinnwirteln und doppelt gelochten Tonscheiben. Große Mengen von Tierfigürchen, rund 200 (Stiere, Widder, Pferde, Schweine, Bären und eventuell Hunde) lagen auf aus Lehm und gebranntem Ton gefertigten Altären oder um Opferpodeste, also zu den sicher zu kultischen Zwecken genutzten Herdanlagen. Das Verbreitungsgebiet liegt innerhalb des Karpatenbeckens, meist auf befestigten Höhensiedlungen, in Siebenbürgen, dem östlichen Alföld und dem Donau-Theiß-Zwischenstromland, dem Verbreitungsgebiet der Füzesabony-MezöcsátGruppe sowie in den westlichen Ausläufern des Karpatenbeckens. Die westlichsten Verträter wie Ormož oder Brno-Obřany datieren in die späte Urnenfelderzeit, bzw, in die späte Urnenfelderzeit-/frühe Hallstattzeit am Beginn des 8 . Jahrh. v. Chr. Wie Metzner-Nebelsick schreibt, „wenn man die Tierfigürchen losgelößt von Begriffen wie Kommunikationsstrukturen oder Kultpraktiken betrachtet und auf die profane Ebene rückt, so können sie sicher auch ein als zwar religiös motivierender, aber dennoch realer bildlicher Ausdruck der Lebenswelt von Viehzüchter-Gesellschaften betrachtet werden. Dabei ist sicher die Auswahl der dargestellten Tiere - zumeist Rinder und Pferde, seltener Schafe und noch seltener Schweine oder andere Tiere - nicht zufällig und trägt der damals hauptsächlich üblichen Haltung und Wertschätzung von Herdenvieh Rechnung“ (Metzner-Nebelsick 1998, 396f., Abb. 27). Zusammenfassend läßt sich sagen, dass die Verbreitungskarte der Tierplastiken um weitere Stücke aus der Westslowakei zu ergänzen ist: Aus Pobedim, Devín, Pusté Úlany, sowie aus Mähren und Südwestböhmen und weiter bis nach Nordostbayern, wo sie ebenfalls ein weitverbreitetes Phänomen belegen (Studeniková 2004, 366, Böhmen: in der Nynice-Gruppe - Šaldová 1968). Weiter sind vergleichbare Stücke auch in der Lausitzer Kultur vertreten (Gediga 1970, Abb. 2, 3, 33-40). Abge- sehen von den tönernen sind manchmal auch kleine bronzene Tierplastiken bekannt, beispielsweise aus Brno-Obřany/Mähren (Adámek 1961, Taf. 118:1, 38:6, 69:7; Kmetová - StegmannRajtár 2014, 150) oder Podhradie/Westslowakei (Studeníková 2004, Abb. 1, 1-2). An dieser Stelle zu erwähnen ist auch der bemerkenswerte hallstattzeitliche Fundort in Südböhmen - der Berg Burkovák bei Nemějice, Kr. Písek, der als Kultareal betrachtet wird, weil dort u. a. auch zahlreiche kleine Tierplastiken aus Ton entdeckt wurden und der von den Ausgräbern mit den venetischen Heiligtümern in Nordostitalien verglichen wird (Chytráček - Chvojka - John - Michálek 2009).

Das Knochenplättchen mit zoomorpher Darstellung von zwei Hirschkühen von Pusté Úlany ist vor allem mit ähnlichen Bildmotiven auf Werken der älteren Situlenkunst vergleichbar (Frey 1969, 81). Die Idee das Stück aus Knochenmaterial herzustellen ist nicht auf die heimische Bearbeitung von Knochen oder Horn zurückzuführen, die ganz abweichenden Charakter hat (Studeniková 2005, 73; 2012, 152). Halbrelief verzierte Werke mit antrophomorphen und zoomorphen Darstellungen, vor allem aus Elfenbein, sind typisch für pizenische und etruskische Kunst, von wo Votivplättchen aus venetischen Heiligtümern bekannt sind, beispielsweise aus Vicenza (Roth 1978). Solche reliefverzierten Knochenarbeiten bildeten den Belag verschiedener kleiner Kästchen oder dienten als Anhänger, alleinstehende Plastiken, oder als Bügelbelag von Fibeln mit Knochen- und Bernsteinperlen, wie sie in der Höhensiedlung Smolenice-Molpír (Dušek - Dušek 1984, Taf. 129:22; Parzinger - Stegmann-Rajtár 1988, Abb. 3:5; Marková - Stegmann-Rajtár 2009, Abb. 2:6; 3:5), im Grab von Špačince (Pichlerová 1963, 113f., StegmannRajtár 1992, Abb. 40:3) oder in der befestigten Siedlung von Brno-Obřany (Adámek 1961, Taf. 27:3) gefunden wurden. Fibeln mit Knochen- 
und Bernsteinbesatz kommen in reichen Frauengräbern im südostalpinen und estensischen Bereich des öffteren vor, beispielsweise in Nesactium auf Istrien, oder im slowenischen Vače. Nach Meinung Biba Teržan's belegen sie die Verbindung Istriens mit der Apeninhalbinsel (Teržan 1995, 99f., Abb. 37, 3-5). Wertvolle Erzeugnisse aus Elfenbein waren vor allem für pizenische und etruskische Kunst stellvertretend, eine Konzentration ist vom picenischen Gebiet, entlang der Handelswege, die nach Etrurien führten und die in die Hälfte, bzw. in das dritte Viertel des 7. bis zur Mitte des 6 . Jahrh. vor Chr. datiert sind, bekannt (Studeniková 2005, 73). In einfacher glatter Form ohne Reliefverzierung sind Fragmente aus Horn gearbeiteter Plättchen auch im Fürstengrab von Atenica bei Čačak in Westserbien gefunden worden, wo sie Ratko Vasič als Import aus archaischer, bzw. spätarchaischer Zeit auf den Balkan interpretiert (Vasič 1992, 53-66, Abb. 1-3; Studeniková 2005, 73). Die einzelnen Plättchen aus Atenica waren möglicherweise der Belag eines Holzkästchens, wie Befestigungspuren zeigen. Wie B. Teržan schreibt „bei erfolgter Akkulturation beobachtet man einen komplexen Prozeß, der sich sowohl in vielen Bereichen des Materiellen, wie auch in Kunst und Religion (in Bestattungssitten, in der Situlenkunst usw.) ausdrückt. Sie kann sich vermutlich vor allem wegen Ähnlichkeiten in den sozialstrukturellen Systemen und im kulturellen Entwicklungsgrad einerseits von archaischetruskischen protourbanen und südostalpinen sowie mitteleuropäischen präurbanen Gesellschaften andererseits durchsetzen“ (Teržan 1995). Echte Importgüter können ebenso unterschiedlich interpretiert werden. Meist liegen sie aus hervorgehobenen Gräbern der Oberschicht vor. Auf jeden Fall kann man in dieser Ware eine Kategorie von Luxus- und Prestigegütern erkennen. Es liegen Verbindungen zwischen istrischen und südostalpinen
Kulturgruppen vor. Im Frauengrab von Vače befinden sich neben dem reichen Bernsteinschmuck - Perlenkette und Ohrringe wie im Grab 4 in Stična - mehrere preziöse Stücke aus Horn (dabei handelt es sich um Horn eines Rothirsches) - eine überdimensionierte Fibel mit Hornbesatz und Rosetten, ein ornamentierter Zylinder (vielleicht eine Duftdose) sowie zwei Frauen- und ein Reiterfigürchen. Ähnliche, obgleich überwiegend kleinere Fibeln mit Knochenbesatz kommen auch in anderen Frauengräbern im südostalpinen und estensischen Bereich des öfteren vor (Teržan 1995, 99, Abb. 37).

Die Siedlung sowie die Grabhügel von $\mathrm{Pu}$ sté Úlany liegen etwa $8 \mathrm{~km}$ östlich vom alt bekannten Grabhügelfeld Reca. Die Bestattungsplätze sowie die benachbarten offenen Siedlungen der westslowakischen Tiefebene, beispielsweise Vel'ký Grob, Vajnory, Ivanka, Abrahám, Hoste, Sered' oder Nové Košariská belegen eine blühende regionale Hallstattkultur westlich der Waag. Vor allem die erst in neuster Zeit entdeckte Siedlung von Nové Košariská, die neben den bekannten Grabhügeln liegt, belegt mit besonderer Deutlichkeit die Bedeutung dieser Region (Belanová Čambal - Stegmann-Rajtár 2007).

Im Fall des Knochenplättchens von der Siedlung in Pusté Úlany könnte es sich um einen Kästchenbelag oder um einen Anhänger handeln. Figurale Motive (anthropomorphe wie auch zoomorphe) auf Elfenbeinbeinplättchen kommen in picenischer sowie etruskischer Kunst vor (Studeníková 2005, 73). Die Siedlung von Pusté Úlany kann man als einen Platz bezeichnen, der scheinbar über längere Zeit und wiederholt als Opfergrube benützt wurde, wenn man die Funde im Zusammenhang mit den Befunden interpretiert. Sie stammen aus unterschiedlichen Perioden, dienten aber vermutlich dem gleichen Zweck - der Opferung. 


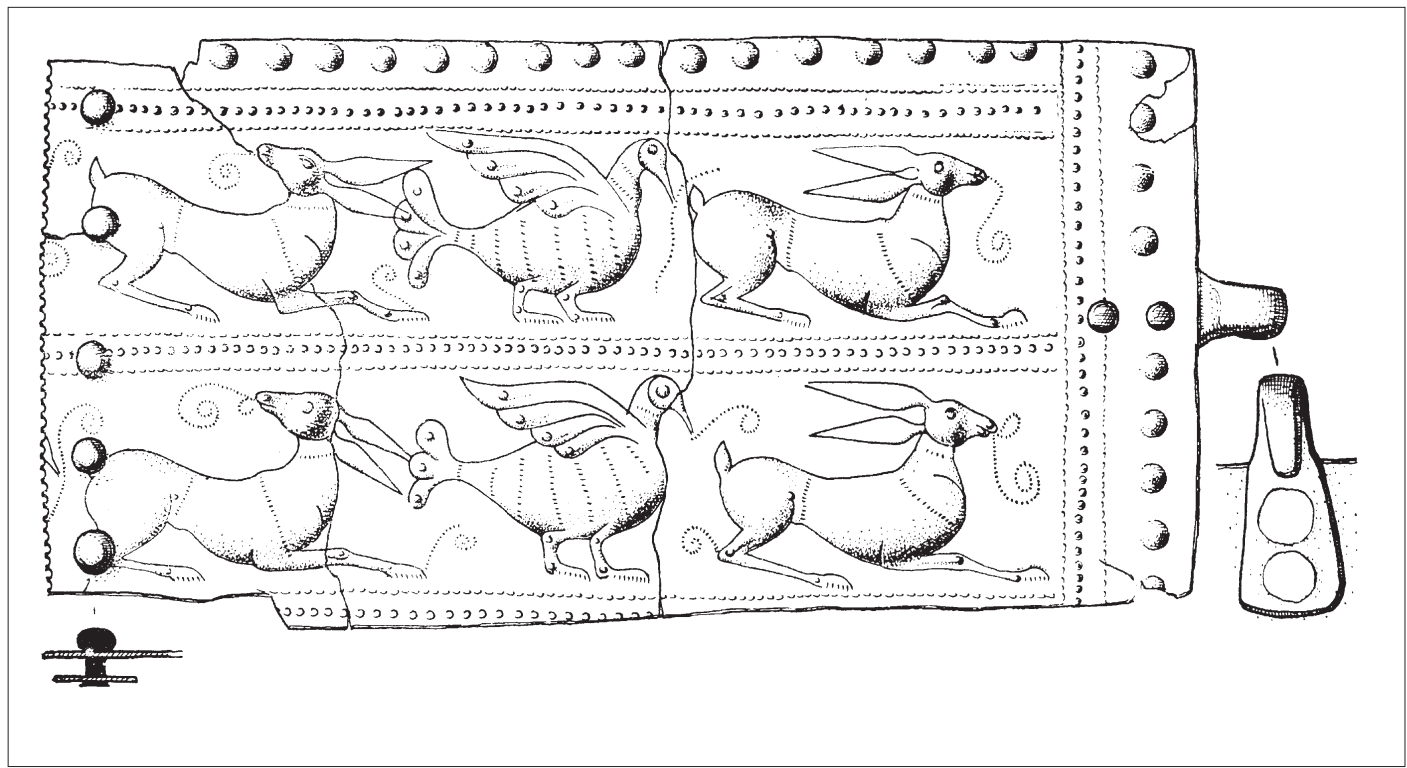

Abb. 5. Gürtelblech von Vače (nach Starè 1955, Taf. 44).

\section{Die Funde von Pusté Úl'any im regionalen und überregionalen Zusammenhang}

Das Bild von der hallstattzeitlichen Siedlungsstruktur im nördlichen Randbereich des ostalpin-westpannonischen Raumes hat sich in den letzten Jahren durch die Entdeckung und Freilegung zahlreicher neuer Siedlungsplätze wesentlich geändert (Stegmann-Rajtár 2002; 2004; 2005a; 2005b; 2009; Teržan 1990; 1995; 1998). Auch wenn der ungenügende Publikationsstand keine endgültigen Aussagen und kein einheitliches Bild zur Beurteilung des damaligen kulturellen und gesellschaftlichen Lebens erbracht hat, geben einige außergewöhnlichen Neufunde wichtige Hinweise zur Bedeutung der Fundplätze. Die Aufmerksamkeit der Forschung war in früheren Jahrzehnten hauptsächlich auf die Freilegung der Grabhügelgruppen gerichtet, wie beispielsweise Reca, Nové Košariská, Pusté Úlany, Dedinka, Janíky-Dolné Janíky und Biely Kostol (Studeniková 1996; 2005; Urminský 2001).
Seit dieser Zeit hat sich der Forschungsstand zur Hallstattzeit erheblich geändert und die Fundzahl ist deutlich gewachsen (Stegmann-Rajtár 2002; Brosseder 2004; Müller 2012). Erst vor kurzer Zeit sind zu drei der genannten Bestattungsplätze, nämlich zu Nové Košariská (Belanová - Čambal - Stegmann-Rajtár 2007), zu Pusté Úlany (König 2003; 2005) und zu Janíky-Dolné Janíky (Čambal - Gregor 2006) auch die dazugehörigen Siedlungen entdeckt und teilweise auch freigelegt worden.

Das breitere Umfeld von Pusté Úlany (Abb. 1) befindet sich im Kontaktgebiet des mitteldonauländischen und lausitzer Kulturkreises (Stegmann-Rajtár 2002). In der späten Urnenfelderzeit waren auf der unweit liegenden Fundstelle Abrahám mehrere Brandgräber der Lausitzer Kultur untersucht worden (Struhár - Fodor 1998; 2002). Bekannte Altfunde von mehreren hallstattzeitlichen Fibeln, sehr wahrscheinlich aus Gräbern, belegen die Bedeutung von Abrahám auch in dieser Periode (Paulik 1960). In Pusté Úlany, in der Flur „Role nad 


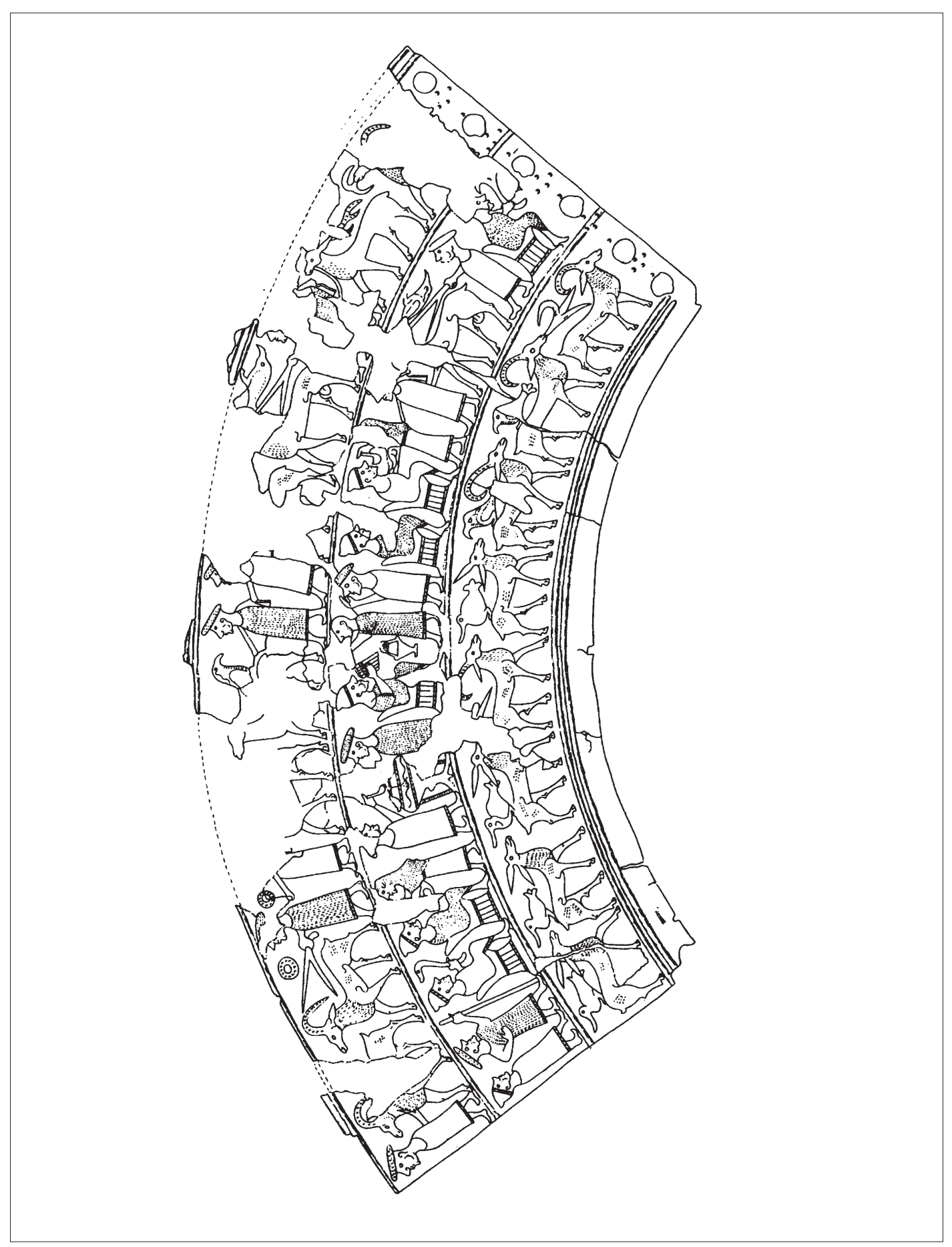

Abb. 6. Magdalenska Gora, Situla in Wien (nach Huth 2003, Taf. 57). 
Silvášmi“, erstreckte sich in der Hallstattzeit eine Grabhügelgruppe (Studeniková 1981), sowie in unmittelbarer Nähe in der Flur „Hlavná ulica" auch die in diesem Beitrag besprochene zeitgleiche Siedlung (König 2005). In einer schon früher bekannt gewordenen Siedlung in der Flur „Intravilán“ wurden während einer Rettungsgrabung mehrere Gruben, ebenfalls aus der Hallstattzeit, freigelegt (Veliačik - Romsauer 1994, 155 f., Abb. 40). Das umfangreiche Scherbenmaterial aus der Siedlungsgrube von Pusté Úlany „Hlavná ulica“ kann allgemein in die lokale Entwicklung der Kalenderberggruppe eingeordnet werden. Form, Verzierung und Machart der Keramik ist auch von anderen offenen Flachsiedlungen, wie beispielsweise Sered' oder Hoste, sowie von der befestigten Siedlung Smolenice-Molpír vorhanden (Paulik 1956; 1958; Bujna - Romsauer 1984; Dušek Dušek 1984; 1995; Stegmann-Rajtár 1998; Müller 2012). Eine genaue Zeitstellung der Keramik ist schwierig, aber ramenhaft kann das Fundmaterial ins 7. Jahr. oder an den Beginn des 6. Jahrh. vor Chr. eingeordnet werden. Eine genauere Zeitstellung des figürlich verzierten Knochenplättchens von Pusté Úlany kann anhand von Vergleichsfunden zum norditalischen Raum hin an das Ende des 7. Jahrh. vor Chr. festlegt werden (Müller 2012, 260). Auf jeden Fall sind Funde der Vekerzug-Kultur von dieser Fundstelle (weder von den Grabhügeln, noch von der Siedlung) nicht bekannt, was ebenfalls eine wichtige Feststellung für diesen Raum bedeutet. Ein nur in 12 km Luftline entfernt liegendes Flachgräberfelder der Vekerzug-Kultur mit Körper- sowie Brandgräbern ist jedoch von Senec bekannt (Chropouský 1962; Kozubová 2013, Katalóg 274-282).

Die Fortsetzung der Tradition figürlich verzierter Kegelhalsgefäße in den Grabhügeln der Kalenderberggruppe, wie beispielsweise in Nové Košariská oder Reca, stellen wir jedoch in den Grabhügeln von Pusté Úlany nicht fest. Die letztgenannten Grabhügel gehören zwar rahmenhaft in die gleiche Zeit wie die anderen Grabhügel, d. h. in die Stufen $\mathrm{HaC}$ bis $\mathrm{HaD}$ 1, weil jedoch in ihnen lediglich Keramik und kein Metall enthalten war, kann das Ende der Belegung von Pusté Úlany nicht genauer festgelegt werden. Geht man allgemein vom typologischen Formenspektrum der Gefäße in der Siedlung von Pusté Úlany aus, so kann das Fundmaterial nicht jünger als $\mathrm{HaD} 1$ eingeordnet werden. Die Belegung der Siedlung scheint möglicherweise in den gleichen Zeitraum zu fallen wie der der Grabhügel (HaC - HaD 1). Auf jeden Fall liegt jedoch Keramik der Vekerzug-Kultur in Pusté Úlany nicht vor, so daß ihre Belegung älter ist, als der Beginn der Flachgräberfelder der Vekerzug-Kultur in dieser Region (Bučany, Senec u.a.). Der aussergewöhnliche Fund des Knochenbelags von Pusté Úlany war vermutlich Teil eines Prestigeobjektes und wenn auch von Werken der Situlenkunst weit entfernt, bleibt es naheliegend, dass er zeitlich mit Werken der älteren Situlenkunst zusammengeht. Er belegt gleichzeitig das Weiterleiten der Tradition der Situlenkunst auch in den Randgebieten der nordöstlichen Hallstattkultur. Diese weitreichenden Kontakte setzten sich während der späten Hallstattzeit fort, also in einer Zeit, als es in der Westslowakei zu einer allmählichen Überschichtung mit der Vekerzug-Kultur gekommen war (Parzinger - Stegmann-Rajtár 1988; Romsauer 1996; Stegmann-Rajtár 2009, 113-115). Auch die frühlatènezeitliche Siedlung von Bratislava-Dúbravka belegt, dass noch in der frühesten Latènezeit Keramik hallstättischer Machart weiterlebte (Stegmann-Rajtár 1996, Abb. 7: 6; 9: 7.9; 10: 5.6). Der kulturelle Wandlungsprozess in der Südwestslowakei hat sich also etappenweise entwickelt, wie es Gräberfelder und Siedlungen deutlich machen. 
Ein Exkurs zur späthallstatt- und frühlatènezeitlichen Entwicklung in der Südwestslowakei

Im Zusammenhang mit der Siedlung von Pusté Úlany und ihrer genaueren zeitlichen Einordnung stellt sich auch die Frage nach der chronologischen Entwicklung in der Südwestslowakei an der Wende von der Späthallstattzur Frühlatènezeit. Einen wichtigen Hinweis zu dieser Problematik im Verbreitungsgebiet der Osthallstattkultur gibt uns bis heute vor allem das Flachgräberfeld Bučany, nordöstlich von Trnava, das Hermann Parzinger in zwei chronologische Gruppen gliederte (Bujna - Romsauer 1983; Parzinger 1989, 105-106; Stegmann-Rajtár 1996, 468). Aufgrund der Vergesellschaftung aussagekräftiger Metall- und Keramikfunde hat Parzinger zwei chronologische Gruppen unterschieden (Parzinger 1989, Taf. 132; 133; 134:1). Für Bučany I ist noch Keramik der Hallstattkultur lokaler Ausprägung charakteristisch, d. h. enthalten sind auch Schalen mit Einglättmuster und Tassen mit überhöhtem Hörnerhenkel; den Einfluss aus dem Bereich der Szentes-Vekerzug-Kultur belegen sog. pontische Ohr- oder Haarringe, Pferdegeschirrteile sowie eine doppelkonische Tasse mit überhöhtem Bandhenkel. Obwohl Bučany I kulturell noch späthallstättisch geprägt ist, hat es schon frühlatènezeitliches Alter, wie die Certosafibel XIII mit rechteckig gebogener Sehne und eine Fußzierfibel aus Eisen belegen (Parzinger 1989, Taf. 132: 1, 2). Im jüngeren Bučany II erscheint dann eine Vielzahl neuer Metall- wie auch Keramiktypen, die kulturell dem frühen Latènestil entsprechen (Parzinger 1989, Taf. 133).

Auch die neu entdeckte befestigte Höhensiedlung der Frühlatènezeit in Horné Orešany „Slepý vrch“ (Kr. Trnava), die in 544 m o.d.M. am Osthang der Kleinen Karpaten liegt, beginnt die Besiedlung in der Frühlatènezeit (Horizont 9/Dürnberg III 1a und Horizont 10/
Dürnberg III 1b nach Parzinger 1989, Beilage). Beide Horizonte sind frühlatènezeitlich und fallen in die Stufe LtA. Die wichtigsten Funde sind bronzene Tierkopf- und Maskenfibeln aus der jüngeren Phase der Frühlatènezeit, die offenbar die höchste Blütezeit der Besiedlung auf der Höhensiedlung repräsentieren. Die Fibeln sind gute Beispiele frühkeltischer Kunst der Stufe LtA, die in diesem Gebiet zum ersten Mal von einer befestigten Höhensiedlung stammen. Sie belegen die Bedeutung dieses Platzes als der östlichsten Fundstelle dieser Art. Aber auch andere vereinzelte Funde - wahrscheinlich ebenfalls von der Fundstelle, jedoch nicht von der Ausgrabung selbst, belegen, dass der Beginn der Besiedlung schon im Verlauf der Späthallstattzeit einsetzte (Pieta 2007, 305). Während der Blüte der Vekerzug-Kultur (HaD) wurden vor allem Niederungssiedlungen angelegt, dagegen hat man mit der beginnenden Frühlatènezeit auch mit dem Aufbau von Höhensiedlungen begonnen. Die offene Siedlung Bratislava-Dúbravka, die Höhensiedlung Horné Orešany „Slepý vrch“ sowie das Gräberfeld Bučany laufen in etwa zeitlich parallel miteinander. Die Fundstellen Vrbové und Hubina liegen nicht weit entfernt und belegen die $\mathrm{HaD} / \mathrm{LtA}$ Besiedlung auch in offenen Siedlungen. Damit ist der Forschungsstand zur Stufe LtA im Bereich der Westslowakei seit den letzten Jahren ziemlich klar umrissen und relativ-chronologisch gut verankert. Mit dem Gräberfeld Bučany beobachtet man, wie sich in der Westslowakei der kulturelle Wandel von der Späthallstatt- in die Frühlatènezeit vollzogen hat (Bujna - Romsauer 1983; Parzinger 1989, 105-106). Die älteren Gräber der Phase Bučany I gehören nach den Metallfunden bereits in die früheste Latènezeit, wobei sie noch mit Keramik der Vekerzug-Kultur vergesellschaftet sind. Die erst vor kurzer Zeit entdeckte befestigte Siedlung von Horné Orešany, nur wenig südlich von der befestigten Höhensiedlung Smolenice-Molpír, belegt 


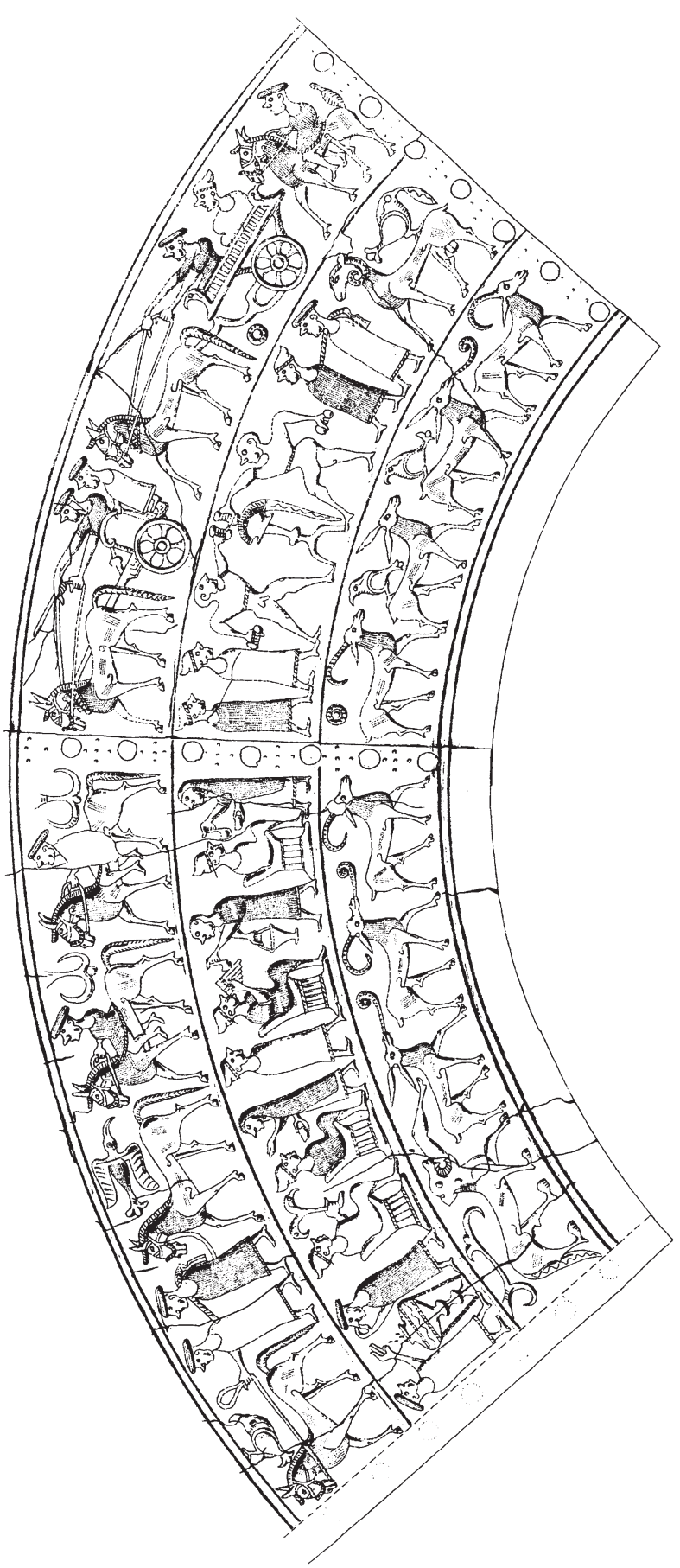

Abb. 7. Vače, Situla in Ljubljana (nach Huth 2003, Taf. 56). 
in einer bis jetzt nie dagewesenen Deutlichkeit den stark ausgeprägten frühlatènezeitlichen Besiedlungshorizont in diesem Gebiet (Parzinger Stegmann-Rajtár 1988; Parzinger 1989, Beilage). Es ist von großer Bedeutung, dass diese nur in $6 \mathrm{~km}$ Luftlinie von Smolenice-Molpír entfernte Höhensiedlung auch in der Hallstattzeit besiedelt war, wie Einzelfunde von Fibeln deutlich machen.

Wie bereits an anderer Stelle betont, ist für die überregionale Chronologie der Späthallstattzeit auch das Grab von Atenica bei Čačak, das von B. Teržan in das zweite Viertel des 6. Jahrhunderts umdatiert wurde, von großer Bedeutung (Teržan 1998, 518). In einfacher glatter Form ohne Reliefverzierung sind Fragmente aus Horn gearbeiteter Plättchen auch in diesem Fürstengrab gefunden worden, wo sie R. Vasič als Import aus archaischer, bzw. spätarchaischer Zeit auf den Balkan interpretiert (Vasič 1992, 53-66, Abb. 1-3; Studeniková 2005, 73). Die einzelnen Reliefplättchen aus Atenica waren möglicherweise der Belag eines Holzkästchens, wie Befestigungspuren zeigen.

Der außergewöhnliche Fund und die besonderen Fundumstände in der Grube von Pusté Úlany „Hlavná ulica“ belegen, dass er zur Zeit der Endphase der regionalen Kalenderberggruppe in den Boden kam und dass er möglicherweise mit einer Opferung zusammenhängt. Beispiele aus der jüngeren Situlenkunst, z. B. aus Tirol zeigen, dass die Situlen zum großen Teil von Opferplätzen stammen und deshalb meistens nur in Fragmenten erhalten sind. Den Fund von Pusté Úlany sollte man sicher nicht überbewerten, aber auch im südwestslowakischen Randgebiet der Hallstattkultur überrascht er nicht. Wie Parzinger schreibt, ist dieser Gedanke nicht neu. Bereits Dämmer und Gleirscher glaubten - eher beiläufig - in den venetischen Seeheiligtümern ebenso wie in den alpinen Brandopferplätzen die Hinterlassenschaften jener Personenkreise zu erkennen, die auch auf den Situlen wiederkehren, ohne diesen Gedanken aber detaillierter auszuarbeiten (Parzinger - Nekvasil - Barth 1995, 219). Es gibt jedoch noch einen weiteren Aspekt, der den gesellschaftlichen Stellenwert des Opfers verdeutlicht: Die Selbstdarstellung durch die Opfergabe. Das Opfer - neben dem Gebet sinnfälligste Äußerung der religiösen Bindung an eine Gottheit. Gebet und Opfer seien damit gleichsam eine Überhöhung zwischenmenschlicher Beziehungen (Parzinger - Nekvasil - Barth 1995, 221). Welche Mächte das kultisch-religiöse Leben bestimmt haben, bleibt natürlich unbekannt (Parzinger - Nekvasil - Barth 1995, 207). Des Weiteren ist zu bemerken, dass Metallgegenstände (Trachtschmuck) bei den inneralpinen Opferstellen wesentlich zahlreicher begegnen als bei der nördlichen Gruppe, wo diese Fundgattung fast vollständig fehlt (Parzinger - Nekvasil - Barth 1995, 219221). Die Gemeinsamkeiten der venetischen Heiligtümer, in denen Votivtäfelchen aus Opferfunden stammen, belegen eindeutige Gemeinsamkeiten mit den alpinen Brandopferplätzen, die nicht zu übersehen sind (Parzinger - Nekvasil - Barth 1995, 212, Abb. 9). Zahlreich sind aus den Heiligtümern Votivbleche überliefert. Auf den häufigen Fundstücken fehlen aber weitgehend szenische Schilderungen, wie wir sie in der Situlenkunst haben. Das Motiv des Tieres hat sich bis in die Frühlatènezeit fortgesetzt (Frey 2007, 778-779). Auch auf den im Heiligtum von Vicenza gefundenen 200 Stück verzierter Kleinbleche, fehlen weitgehend szenische Schilderungen (Roth 1978). Zusammenfassend kann man sagen, dass der Fund von Pusté Úlany ein Prestigeobjekt war, der eindeutig mit Werken der Situlenkunst zusammenhängt. Er belegt die Anlehnung und den Ideentransfer an die religiöse Vorstellungewelt nach Vorbild südlicher Hochkultur. 
1) S. Stegmann-Rajtár: Complesso culturale di Hallstatt orientale e le sue relazioni con il sud. Vortrag im Museo nazionale preistorico etnografico Luigi Pigorini, Rom 2006.

Der vorliegende Beitrag ist die überarbeitete Fassung meines am 2. 10. 2009 im Kelten-Römer Museum Manching gehaltenen Vortrags im Rahmen der Ausstellung „Situlen - Bilderwelten zwischen Etruskern und Kelten auf antikem Weingeschirr".

\section{Literaturverzeichnis}

Adámek, F. 1961: Pravěké hradisko u Obřan. Brno. Belanová, T. - Čambal, R. - Stegmann-Rajtár, S. 2007: Die Weberin von Nové Košariská - Die Webstuhlbefunde in der Siedlung von Nové Košariská im Vergleich mit ähnlichen Fundplätzen des östlichen Hallstattkulturkreises. In: Blečić, M. - Črešnar, M. - Hänsel, B. - Hellmuth, A. - Kaiser, E. - MetznerNebelsick, C. (Hrsg.): Scripta praehistorica in honorem Biba Teržan. Situla 44. Ljubljana, 419-434.

Brosseder, U. 2004: Studien zur Ornamentik hallstattzeitlicher Keramik zwischen Rhônetal und Karpatenbekken. Universitätsforsch. Prähist. Arch. 106. Bonn.

Bujna, J. - Romsauer, P. 1983: Späthallstatt- und frühlatènzeitliches Gräberfeld in Bučany, Slovenská archeológia XXXI, 1983, 227-324.

Bujna, J. - Romsauer, P. 1984: Halštatské sídlisko v Hostiach. Slovenská archeológia XXXII, 431-452.

Čambal, R. - Gregor, M. 2007: Halštatská chata v Janíkoch, čast' Dolné Janíky. Zborník Slovenského národného múzea CI, Archeológia 17, 57-86.

Chropovský, B. 1962: Birituálne skýtsko-halštatské pohrebisko v Senci. Štúdijné zvesti AÚSAV Nitra 9, 131-142.

Chytráček, M. - Chvojka,O. - John, J. - Michálek, J. 2009: Halštatský kultovní areál na vrchu Burkovák u Nemějic. Archeol. Rozhledy, LXI, 183-217.

Dušek, M. - Dušek, S. 1984: Smolenice-Molpír - Befestigter Fürstensitz der Hallstattzeit I. Materialia Archaeologica Slovaca 6, Nitra.

Dušek, M. - Dušek, S. 1995: Smolenice-Molpír - Befestigter Fürstensitz der Hallstattzeit II. Materialia Archaeologica Slovaca 13, Nitra.

Frey, O.-H. 1966: Der Ostalpenraum und die antike Welt in der frühen Eisenzeit. Germania 44, 48-66.
Frey, O.-H. 1969: Die Entstehung der Situlenkunst. Studien zur figürlich verzierten Toreutik von Este. Römisch-Germanische Forschungen 31. Berlin.

Frey, O.-H. 2005: Situlenkunst. Reallexikon der Germanischen Altertumskunde 38. Walter de Gruyter. Berlin - New York, 527-535.

Frey, O.-H. 2007: Über die Ostalpen zur Keltiké. Beziehungen zwischen Situlen-/Este-Kunst und dem Latène A-Kreis. In: Blečić, M. - Črešnar, M. - Hänsel, B. - Hellmuth, A. - Kaiser, E. - Metzner-Nebelsick, C. (Hrsg.): Scripta praehistorica in honorem Biba Teržan. Situla 44. Ljubljana, 777-788.

Gediga, B. 1970: Motywy figuralne w sztuce ludności kultury luzyckiej. Wroclaw - Warszawa - Krakow.

Huth, Ch. 2003: Menschenbilder und Menschenbild. Anthropomorphe Bildwerke der frühen Eisenzeit. Berlin.

Kmetová, P. - Stegmann-Rajtár, S. 2014: Zur symbolischen Bestattung von Pferdeschädeln in Gräbern der späten Urnenfelder- und Hallstattzeit. K simboliki konjskich lobanj v grobovih iz poznega žarnogrobiščnega in starejšega halštatskega obdobja (Povzetek). In: Tecco Hvala, S. (Hrsg.): Studia Praehistorica in Honorem Janez Dular. Ljubljana, 149-166.

Kozubová, A. 2013: Pohrebiská vekerzugskej kultúry v Chotíne na juhozápadnom Slovensku. Vyhodnotenie. Katalóg (S dodatkom: Pohrebisko vekerzugskej kultúry v Senci-Štrkovej kolónii). Dissertationes archaeologicae Bratislavenses 1, Bratislava.

König, T. 2003: Halštatský objekt z Pustých Úlan. Zborník Slovenského národného múzea XCVII, Archeológia 13, 93-118.

König, T. 2005: Nálezy z kultového objektu v Pustých Úlanoch. In: Studeníková, E. (Hrsg.): Južné vplyvy a ich odraz v kultúrnom vývoji mladšieho praveku na južnom Dunaji. Studia Archaeologica et mediavalia VII. Bratislava, 89-98. 
Kriss, H. 1962: Die Nachlebende Tradition des Situlenstils. In: Situlenkunst zwischen Po und Donau. Katalog zur Ausstellung. Wien, 81-87.

Marková, K. - Stegmann-Rajtár, S. 2009: Amber in the Context of Cultural Interactions in the Carpathian Basin in the Early Iron Age. In: Palavestra, A. - Beck, C. W. - Todd, J. M. (eds.): Amber in Archaeology. Proceedings of the Fifth International Conference on Amber in Archaeology, Belgrade 2006. Belgrade 2009, 110-123.

Metzner-Nebelsick, C. 1998: Abschied von den „ThrakoKimmeriern"? - Neue Aspekte der Interaktion zwischen karpatenländischen Kulturgruppen der späten Bronze- und frühen Eisenzeit mit der osteuropäischen Steppenkoine. In: Hänsel, B. Machnik, J. (Hrsg.): Das Karpatenbecken und die osteuropäische Steppe. Nomadenbewegungen und Kulturaustausch in den vorgeschichtlichen Metallzeizen (4000-500 v. Chr.). Südosteuropa-Schriften. Bd. 20. Prähistorische Archäologie in Südosteuropa 12, München- Rahden/Westf., 361-422.

Metzner-Nebelsick, C. 2002: Der „Thrako-Kimmerische“ Formenkreis aus der Sicht der Urnenfelder- und Hallstattzeit im südöstlichen Pannonien. Vorgeschichtliche Forschungen. Bd. 23. Rahden/ Westf.

Müller, S. 2012: Smolenice-Molpír, Sered' und Ratkovce. Studien zu Siedlungen der frühen Eisenzeit in der Südwestslowakei. Universitätsforschungen zur prähistorischen Archäologie 220, Teil 1 und 2. Bonn.

Nebelsick, L. D. 1992: Figürliche Kunst der Hallstattzeit am Nordostalpengebiet im Spannungsfeld zwischen alteuropäischer Tradition und italischem Lebensstil. In: Festschrift zum 50 jährigen Bestehen des Institits für Ur- und Frühgeschichte Leopold-Franzens-Universität Innsbruck. Universitätsforschungen prähistorischer Archäologie 8. Bonn, 307-317.

Nebelsick, L. D. 2007: Die Kalenderberggruppe der Hallstattzeit am Nordostalpengebiet. In: Nebelsick, L.D. - Eibner, A. - Lauermann, E. - Neugebauer, J.-W. (Hrsg.): Wissenschaftliche Schrifftenreihe Niederösterreich 106/107/108/109. Wien, 9-128.

Parzinger, H. 1989: Chronologie der Späthallstattund Frühlatènezeit. Studien zu Fundgruppen zwi- schen Mosel und Save. Quellen u. Forschungen Prähistorischer und Provinzialrömischer Archäologie 4. Weinheim.

Parzinger, H. 1991: Inandiktepe - Este - Pozo Moro. Bemerkungen zur frühen Bilderzählung. Bericht der Römisch-Germanischen Kommission 72, 5-44.

Parzinger, H. - Stegmann-Rajtár, S. 1988: SmoleniceMolpír und der Beginn der skythischen Sachkultur in der Südwestslowakei. Prähistorische Zeitschrift 63, 162-178.

Parzinger, H. - Nekvasil, J. - Barth, H. E. 1995: Die Býčí-skála-Höhle. Ein hallstattzeitlicher Höhlenopferplatz in Mähren. Römisch-Germanische Forschungen. Mainz am Rhein.

Paulik, J. 1956: Juhozápadné Slovensko v mladšej dobe halštatskej, Slovenská archeológia IV, 177212.

Paulik, J. 1958: Nové hrobové nálezy z mladšej doby halštatskej na juhozápadnom Slovensku, Slovenská archeológia VI, 361-379.

Paulik, J. 1960: Lod'kovité spony z Abrahámu na Slovensku. Archeologické rozhledy XII, 330-336. Paulik, J. - Chroporský, B. 1971: Spindlerfeldské spony na Slovensku. Zborník Slovenského národného múzea LXV. História 11, 25-47.

Pichlerová, M. 1963: Špačince v praveku a v ranej dobe dejinnej. Zborník Slovenského národného múzea LVII. História 3, 104-125.

Pieta, K. 2007: Der frühlatènezeitliche Burgwall in Horné Orešany, Westslowakei, Vorbericht. Slovenská archeológia LV-2, 295-310.

Plachá, V. - Furmánek, V. 1975: Halštatská jama na Devíne. Zborník Slovenského národného múzea LXIX. História 15, 55-72.

Reich, Ch. 1997: Von nah und fern - Der Hortfund von Spindlersfeld. In: Menghin, W. - Hänsel, B. (Hrsg.): Gaben an die Götter. Schätze der Bronzezeit Europas. Bestandskataloge 4. Berlin, 67-69.

Romsauer, P. 1996: Bemerkungen zur Späthallstattzeit im Nordostalpenraum. In: Jerem, E. - Lippert, A. (Hrsg.): Die Osthallstattkultur. Symposium Sopron 1994. Archaeolingua 7, Budapest, 431-444.

Roth, H. 1978: Venetische Exvoto-Täfelchen aus Vicenza, Corso Palladio, Germania 56, 172-189.

Řihovský, J. 1993: Die Fibeln in Mähren. Prähistorische Bronzefunde XIV, 9. Stuttgart. 
Siegfried-Weiß, A. 1979: Der Ostalpenraum in der Hallstattzeit und seine Beziehungen zum Mittelmeergebiet. Hamburger Beitr. Arch. 6.

Starè, F. 1955: Vače. Arheološki katalogi Slovenije 1. Ljubljana.

Stegmann-Rajtár, S. 1992: Spätbronze- und früheisenzeitliche Fundgruppen des mittleren Donaugebietes. Bericht der Römisch-Germanischen Kommission 73, 29-179.

Stegmann-Rajtár, S. 1996: Eine Siedlung der Späthallstatt-/Frühlatènezeit in Bratislava-Dúbravka (Slowakei). In: Jerem, E. - Lippert, A. (Hrsg.): Die Osthallstattkultur. Symposium Sopron 1994. Archaeolingua 7, Budapest, 455-470.

Stegmann-Rajtár, S. 1998: Spinnen und Weben in Smolenice-Molpír. Ein Beitrag zum wirtschaftlichen und religiös-kultischen Leben der Bewohner des hallstattzeitlichen „Fürstensitzes“. Slovenská archeológia XLVI-2, 263-287.

Stegmann-Rajtár, S. 2002: Früheisenzeitliche Fernverbindungen entlang dem Ostalpenraum. In: Lang, A. - Salač, V. (Hrsg.): Fernkontakte in der Eisenzeit, Konferenz Liblice 2000. Praha, 254-269.

Stegmann-Rajtár, S. 2004: Die slowakisch-deutschen Ausgrabungen auf der befestigten Höhensiedlung Štitáre-Žibrica (Kr. Nitra). Mit Beiträgen von Mária Hajnalová, Lucia Benediková und Róbert Kubinec. In: Chvojka, O. (ed.): Popelnicová pole a doba halštatská. Archeologické výzkumy v jižních Čechách, Supplementum 1. České Budějovice, 503-522.

Stegmann-Rajtár, S. 2005a: Vplyvy juhovýchodoalpských centier na vývoj halštatskej kultúry v stredunajskej oblasti. In: Studeníková, E. (Hrsg.): Južné vplyvy a ich odraz v kultúrnom vývoj mladšieho praveku na strednom Dunaji. Studia Archaeologica et mediavalia VII. Bratislava, 60-71.

Stegmann-Rajtár, S. 2005b: Smolenice-Molpír. Reallexikon der Germanischen Altertumskunde 29. Walter de Gruyter. Berlin - New York, 146-156.

Stegmann-Rajtár, S. 2009: Žiarové pohrebisko východohalštatskej a vekerzugskej kultúry v Nových Zámkoch. Príspevok k pohrebiskám doby halštatskej vo východoalpsko-zadunajskej oblasti. Slovenská archeológia LVII-1, 57-116.

Struhár, V. - Fodor, R. 1998: Prieskum lužického urnového pohrebiska v Abraháme. Archeologické výs- kumy a nálezy v roku 1996. Nitra, 156, 267-268.

Struhár, V. - Fodor, R. 2002: Systematický prieskum archeologických lokalít v Abraháme. Archeologické výskumy a nálezy v roku 2001. Nitra, 203205, obr. 156 .

Studeniková, E. 1981: Mohyly z doby halštatskej v Pustých Úlanoch. Zborník Slovenského národného múzea LXXV. História 21, 17-32.

Studeniková, E. 1996: Neue Ausgrabungen hallstattzeitlicher Hügelgräber in der Südwestslowakei. In: Jerem, E. - Lippert, A. (Hrsg.): Die Osthallstattkultur. Symposium Sopron 1994. Archaeolingua 7, Budapest, 497-506.

Studeniková, E. 2004: Plastiky z doby halštatskej zo západného Slovenska. In: Fusek, G. (Hrsg.): Zborník na počesṫ Dariny Bialekovej. Nitra, 363-370.

Studeniková, E. 2005: Kalenderberská kulturá na juhozápadnom Slovensku a juhovýchodná Európa. In: Studeníková, E. (ed.): Južné vplyvy a ich odraz v kultúrnom vývoj mladšieho praveku na strednom Dunaj. Studia Archaeologica et mediavaliaVII. Bratislava, 73-88.

Studeniková, E. 2012: Staršia doba železná (800 - 500 pred n. 1.). In: Šedivý, J. - Štefanovičová, T. (eds.): Dejiny Bratislavy 1. Od počiatkov do prelomu 12. a 13. storočia. Bratislava, 133-156.

Studeniková, E. - Paulik, J. 1983: Osada z doby bronzovej v Pobedime. Bratislava.

Šaldová, V. 1968: Halštatská mohylová kultura v západných Čechách. Pohřebište Nynice I. Památky archeologické LIX, 297-399.

Teržan, B. 1986: Zur Gesellschaftstruktur während der älteren Hallstattzeit im ostalpen-westpannonischem Gebiet. In: L. Török (Hrsg.): Hallstatt Kolloquium Veszprém 1984. Antaeus - Mitteilungen des Archäologischen Instituts der Ungarischen Akademie der Wissenschaften, Beiheft 3, Budapest, 227-243.

Teržan, B. 1990: Starejša železna doba na slovenskem Štajerskem. The Early Iron Age in Slovenian Styria. Katalogi in monografije 25. Ljubljana.

Teržan, B. 1995: Handel und soziale Oberschichten im früheisenzeitlichen Südosteuropa. In: Hänsel, B. (Hrsg.): Handel, Tausch und Verkehr im bronze- und früheisenzeitlichen Europa. Prähistorische Archäologie in Südosteuropa 11. München-Berlin, 81- 159 . 
Teržan, B. 1998: Auswirkungen des skythisch geprägten Kulturkreises auf die hallstattzeitlichen Kulturgruppen Pannoniens und des Ostalpenraumes. In: Hänsel, B. - Machnik, J. (Hrsg.): Das Karpatenbecken und die osteuropäische Steppe. Nomadenbewegungen und Kulturaustausch in den vorgeschichtlichen Metallzeizen (4000-500 v. Chr.). SüdosteuropaSchriften. Bd. 20. Prähistorische Archäologie in Südosteuropa 12. München- Rahden/Westf., 511-560.
Urminský, J. 2001: Halštatské mohylové pohrebisko v Bielom Kostole. Sborník prací Filozofické fakulty Brněnské univerzity $\mathrm{M}$ 6, 77-91.

Vasič, R. 1992: An Etruscan bone box from southwest Serbia and the problem of Late- Archaic imports in the Central Balkan area. Arheološki vestnik 43, 53-66.

Veliačik, L. - Romsauer, P. 1994: Vývoj a vztah osídlenia lužických a stredodunajských popolnicových polí na západnom Slovensku I. Katalóg. Nitra.

\section{Am Vorabend der Situlenkunst - Ein Beitrag zur Bilderzählung in der östlichen Hallstattkultur als Ausdruck religiösen Denkens am Beginn der Eisenzeit}

Das Verbreitungsgebiet der Hallstattkultur ist als Randzone zu den mittelmeerischen Hochkulturen aufzufassen (Abb. 1). Häufigste Bildträger sind vor allem bronzene Prestigegüter wie Eimer/Situlen sowie andere Bronzegefäße, ferner Deckel, Gürtelbleche, Dolchscheiden und andere Metallarbeiten, die wir auch als Ausdruck religiösen Denkens interpretieren. Eine zentrale Stellung der Situlendenkmäler nehmen die toreutischen Arbeiten aus Este ein. Die Entstehung der älteren Situlenkunst fällt in Este in die 2. Hälfte des 7. Jahrhundert vor. Chr. und wirkte sich bis in die Gebiete nordöstlich der Alpen aus. Anregungen zur Entstehung der frühen Bilderzählung aus Este kamen aus dem südlich benachbarten Etrurien. Bei der figürlich verzierten Toreutik von Este ist von besonderem Interesse, dass sie sich über einen ziemlich langen Zeitraum verfolgen lässt. Die letzten Ausläufer der Situlenkunst finden sich mehr in den Randzonen des Verbreitungsgebietes. Das beste Zeugnis dafür, dass es in der Endphase der Hallstattzeit noch zu einer reichen kulturellen Entwicklung kam, bietet die jüngere Situlenkunst (5.-4. Jahrhundert vor Chr). Die Funde dieser Zeit stammen zum großen Teil von Opferplätzen und sind deshalb meistens nur in Fragmenten erhalten geblieben. $\mathrm{Zu}$ einem Ende kommt dieses Kunstschaffen durch die keltische Wanderung und die Überschichtung durch die Latènekultur. In Werken des estensischen Kunstkreises war hauptsächlich das Tierbild vorherrschend. Neben Situlen (Abb. 6; 7) sind vor allem Dolchscheiden (Abb. 4) und Gürtelbleche (Abb. 5)
Bildträger. Die Verbreitung dieser Werke reicht im 5. und 4. Jahrhundert ebenfalls von Tirol bis Krain und im Süden bis Bologna. Die überwiegende Zahl stammt aber aus der Nekropole von Este. Einige Arbeiten sind sicher älter als die etruskische und griechische Kolonisation in der Poebene. Die Tradition dieser Kunst wird auch in späterer Zeit fortgesetzt, als in venetischen Heiligtümern zahlreich Votivbleche angetroffen wurden. Die letzten Reste von figuralverzierten Situlen dürften dann noch einige Zeit als Amulette oder Zierbleche Verwendung gefunden haben.

Figuralverzierte Keramik mit Einzelfiguren war dabei nicht alleine im Ostalpengebiet, sondern auch in Süddeutschland, Böhmen, Nordmähren sowie Mittelschlesien verbreitet. Dagegen bleiben verzierte Tongefäße mit szenischen Elementen, die aufgemalt oder eingeritzt wurden, lediglich auf den Bereich der ostalpinen Kalenderberggruppe beschränkt und gerade sie stehen auch den Denkmälern der besagten Situlenkunst am nächsten. Solche figürliche Darstellungen auf Keramik der Kalenderberggruppe sind hauptsächlich im Begräbnisritual vornehmender Persönlichkeiten, die in Grabhügeln bestattet wurden, kennzeichnend. Die Ursprünge der Figuralkunst kann man weit bis in die Urnenfelderzeit zurückverfolgen und sind von subfigürlichen Motiven abzuleiten. Wesentlich abweichend zu der bis jetzt bekannten figuralverzierten Keramik aus Grabhügeln ist eine außergewöhnlicher Fundart im Bereich der hallstattzeitlichen Siedlung von Pusté Úlany, 
(Kr. Galanta), Flur „Hlavná ulica“, die sich im Randgebiet der Kalenderberggruppe, genauer im Kontaktgebiet mit der Lausitzer Kultur befindet. Die Fundstelle Pusté Úlany liegt etwa $8 \mathrm{~km}$ östlich vom alt bekannten Grabhügelfeld von Reca, sowie unweit von anderen offenen Siedlungen in der westslowakischen Tiefebene wie beispielsweise Velký Grob, Vajnory, Ivanka bei Bratislava, Abrahám, Hoste, Sered' oder Nové Košariská und belegen eine blühende regionale Entwicklung der Hallstattkultur (Abb. 1).

Im Mittelpunkt dieses Beitrags steht für uns die Fundstelle Pusté Úlany wegen des Fundes eines figürlich verzierten, vor allem Knochplättchens aus einer Siedlungsgrube (Abb. 2). Ein Zusammenhang mit Werken der Situlenkunst ist nicht zu bestreiten. Das Knochenplättchen mit zoomorpher Darstellung von zwei stark stilisierten Hirschkühen (Abb. 3: 4) ist für pizenische und etruskische Kunst charakteristisch. Halbrelief verzierte Werke mit antrophound zoomorphen Darstellungen, vor allem aus Elfenbein, sind typisch für pizenische und etruskische Kunst, von wo Votivplättchen, manchmal auch sehr zahlreich, aus venetischen Heiligtümern, beispielsweise aus Vicenza, bekannt sind. Von Bedeutung ist, dass in der Grube nicht nur das Knochenplättchen im Situlenstil sowie Keramik der lokalen Kalenderberggruppe, sondern auch andere bedeutende Funde enthalten sind (Abb. 3: 1-3). Die Siedlungsgrube von Pusté Úlany kann vermutlich man als einen Platz, der scheinbar über längere Zeit und wieder- holt als Opfergrube benützt wurde, wenn man die Funde im Zusammenhang mit den Befunden interpretiert. Sie stammen aus unterschiedlichen Zeitabschnitten, dienten aber vermutlich dem gleichen Zweck - der Opferung. Der Fund von Pusté Úlany war ein Prestigeobjekt, auch wenn von Werken der Situlenkunst weit entfernt, naheliegend bleibt, dass er eindeutig mit dem Nachleben der Situlenkunst im Randgebiet der Hallstattkultur zusammengeht. Er belegt gleichzeitig das Anknüpfen und Weiterleiten an Gebiete und Traditionen die mit der Situlenkunst im Zusammenhang stehen. Der außergewöhnliche Fund und die besonderen Fundumstände der Grube von Pusté Úlany belegen, dass er zur Zeit der Endphase der regionalen Kulturentwicklung (Kalenderberggruppe) zu Boden kam und dass er mit der Opfergrube zusammenhängt. Eine genaue Zeitstellung der Keramik ist schwierig, aber ramenhaft kann das Fundmaterial ins 7. Jahr. oder an den Beginn des 6. Jahrh. vor Chr. eingeordnet werden. Eine genauere Zeitstellung des figürlich verzierten Knochenplättchens von Pusté Úlany kann anhand von Vergleichsfunden zum norditalischen Raum hin an das Ende des 7. Jahrh. vor Chr. festlegt werden. Es steht fest, dass er Teil eines Prestigeobjektes war, der eindeutig mit Werken der Situlenkunst zusammengeht. Er belegt die Anlehnung und Ideentransfer an die religiöse Vorstellungswelt nach Vorbild südlicher Hochkultur.

\section{PhDr. Susanne Stegmann-Rajtár, CSc.}

- Archeologický ústav SAV

Akademická 2, SK-94921 Nitra

zuzana.rajtarova@savba.sk 